\title{
Rapid identification by specific PCR of coagulase- negative staphylococcal species important in hospital infection
}

\author{
S. GRIBALDO, B. COOKSON*, N. SAUNDERS, R. MARPLES* and J. STANLEY \\ Molecular Biology Unit, Virus Reference Division and*Laboratory of Hospital Infection, Central Public Health \\ Laboratory, 61 Colindale Avenue, Londan NW9 5HT
}

\begin{abstract}
Polymerase chain reaction (PCR) identification assays were designed for eight major species of coagulase-negative staphylococci (CNS) on the basis of three variable regions found in the 16S rRNA gene. The PCR assays were tested with 41 staphylococcal strains representing the diversity of staphylococci defined by classical biotyping schemes. Each PCR result was compared with species-specific polymorphism in and around the $16 \mathrm{~S}$ rRNA gene (i.e., 16S ribotype) and the phenotypic identification of the strain in a miniaturised biochemical test gallery (bioMérieux ATB 32 Staph). Twenty-six of the 41 strains were identified by PCR as belonging to one of the eight species for which primers had been designed and none of the remaining strains was misidentified. For 22 of the 26 strains there was complete agreement between the PCR identification, 16S ribotype and ATB identification. For the remaining four strains there was agreement between PCR identification and 16S ribotype. Two National Collection of Type Culture strains were re-assigned to different species and 10 previously unassigned strains were formally speciated for the first time. These PCR assays are suitable for rapid and definitive speciation of CNS.
\end{abstract}

\section{Introduction}

The genus Staphylococcus comprises 32 species, of which the coagulase-positive $S$. aureus is the most important clinically. Thus identification of staphylococci has often been limited to rapid screening for $S$. aureus, with other species simply reported as coagulase-negative staphylococci (CNS). Although previously regarded as harmless commensals and contaminants of skin and mucous membranes, CNS are now recognised to be potential pathogens. They are among the major causative agents of hospital infection, and are particularly associated with the use of medical devices in seriously ill and immunocompromised patients [1]. With increasing realisation of their pathogenic potential, the timely identification of CNS has become a higher priority in the clinical microbiology laboratory.

In 1963 Baird-Parker [2] examined a collection of CNS and micrococci of animal and human origin and

Received 15 Feb. 1996; revised version accepted 25 June 1996.

Corresponding author: Dr J. Stanley. defined six principal biotypes among staphylococci. Biotype SI corresponded to the coagulase-positive species ( $S$. aureus, $S$. intermedius), whilst the others were generally defined as coagulase-negative staphylococci (CNS). Strains of biotypes SII and SV fermented maltose, produced acetoin, and were, respectively, phosphatase positive or negative. Biotype SIII strains were phosphatase positive and unable to produce acetoin. Strains of biotype SIV were phosphatase negative, produced acetoin, but did not ferment most carbohydrates. Strains of biotype SVI were phosphatase negative, produced acetoin and fermented mannitol, but showed a number of otherwise variable biochemical reactions. He also defined eight biotypes of micrococci, some of which are now accepted as staphylococci, notably $S$. saprophyticus. Kloos and Schleifer [3] subsequently examined a collection of CNS from human skin and animals and described a phenotypic scheme that identified 10 staphylococcal species, through the use of a wide. range of sugars, other substrates and incubation temperatures. Examining a more comprehensive collection of human and animal CNS, Marples [4] compared the two phenotypic schemes and found that, apart from SIV and SV, the Baird-Parker biotypes corresponded to species defined by Kloos and 
Schleifer [3]. He also defined four additional biotypes corresponding to CNS species in a 36-biotype scheme for the staphylococci [5]. Ornithine decarboxylasepositive isolates (SVe) described in this study were subsequently described as the new species $S$. lugdunensis [6].

A limitation of biochemical tests in the identification of CNS is the variable expression of certain phenotypic characters. Ambiguity can also result from subjectivity of interpretation of colorimetric tests. Other identification methods, such as multilocus enzyme electrophoresis, whole cell polypeptide analysis or cellular fatty acid composition exist [7-9], but none can alone serve to identify species among the CNS. Thus, there is a need for rapid and accurate species identification by a DNA-based method.

DNA-DNA hybridisation studies formed one of the defining criteria for the current phylogeny of CNS species [10], and analysis of polymorphism in and around the rRNA operon by heterologous rRNA gene probes has been shown to be a powerful tool in identification and typing of bacteria, including staphylococci [11-14]. Six rRNA operons have recently been cloned from $S$. aureus [15]. An oligonucleotide probe complementary to a variable region of the $16 \mathrm{~S}$ rRNA gene sequence was designed which co-identified $S$. epidermidis, $S$. capitis, $S$. caprae and $S$. saccharolyticus. The oligonucleotide acted as primer in polymerase chain reaction (PCR) assays to distinguish $S$. epidermidis from $S$. saprophyticus, but it was not tested against other CNS species [16]. Two PCRs employing primers derived from the 16S rRNA gene sequence were reported to co-identify $S$. epidermidis and $S$. capitis on the one hand, and $S$. haemolyticus alone on the other [17].

The present study sought to develop disciminatory PCR-based identification of CNS species of particular significance in hospital infection due to their prevalence or because they are difficult to identify definitively by phenotypic means, or both. Biotype reference strains of CNS described in the scheme of Marples [4,5], as used by the national reference laboratory for identification of CNS were examined. Reference strains of the biotyping schemes and National Collection of Type Culture (NCTC) strains of CNS species were analysed. Results of the newly developed PCR identification assays were compared with data from $16 \mathrm{~S}$ ribotyping and a commercial biochemical identification kit [18].

\section{Materials and methods}

\section{Bacterial strains, culture conditions and phenotypic tests}

Type strains (designated in this study by the superscript T) and reference strains were obtained from NCTC and the Laboratory of Hospital Infection collection. They were grown overnight on blood agar plates at $37^{\circ} \mathrm{C}$. Phenotypic identification of strains was made by inoculating a gallery of miniaturised biochemical tests (ATB 32 Staph, bioMérieux) [18]. Manufacturers' instructions were followed regarding the duration and temperature of incubation before final visual reading of these tests. The species designation and probability of identification were assigned by APILAB software (bioMérieux).

\section{$16 S$ ribotyping}

Staphylococcal DNA was prepared from overnight plate cultures as previously described [19], except that TE buffer was substituted by TES buffer $(0.1 \mathrm{M} \mathrm{NaCl}$; $10 \mathrm{~mm}$ Tris, pH 8; $1 \mathrm{mM}$ EDTA) and lysis was achieved by resuspending cells in $100 \mu \mathrm{l}$ of lysostaphin $(1 \mathrm{mg} / \mathrm{ml}$ in TES buffer; Sigma) and $50 \mu 1$ of lysozyme $(50 \mathrm{mg} /$ $\mathrm{ml}$; Sigma). A 1500-bp intragenic fragment of the $16 \mathrm{~S}$ rRNA gene was generated by PCR from genomic DNA of $S$. epidermidis ${ }^{T}$ NCTC 11047, with the forward primer 5'AAGAGTTTGATCCTGGCTCAG-3' and the reverse primer 5'GGTTACCTTGTTACGACTT-3' [20]. The amplicon was labelled with biotin-16-dUTP with a random-primed labelling kit (Boehringer Mannheim Biochemica GmbH, Mannheim, Germany). Restriction endonuclease digests of genomic DNA ( $5 \mu \mathrm{g} /$ track) were subjected to electrophoresis in agarose $0.8 \%$ for $15 \mathrm{~h}$ at $50 \mathrm{~V}$. Gels were vacuum-blotted (LKB VacuGene apparatus, Pharmacia Biotech Ltd, Milton Keynes) on to Hybond $\mathrm{N}$ nylon membrane (Amersham Life Science, Bucks). Hybridisation was performed under standard conditions [21] and reactions were visualised colorimetrically with BluGene reagent (Life Technologies). Mol.wt markers were biotinylated Hind III fragments of phage lambda (Life Technologies). The hybridisation patterns so generated were analysed visually. Identical ribotypes were assigned the same number and related ribotypes were designated by postscript letters.

\section{PCR}

Oligonucleotide forward and reverse primers were purchased from Cruachem Ltd, Glasgow, and their compatibility was assessed by the computer program PRIMER [22]. Genomic DNA of test strains was diluted to a concentration of $50 \mathrm{ng} / \mu \mathrm{l}$. Amplification was performed in 25- $\mu$ l volumes of $1 \mathrm{X}$ PCR buffer (Life Technologies) containing $50 \mathrm{ng}$ of genomic DNA, $2.5 \mathrm{mM} \mathrm{MgCl}, 200 \mu \mathrm{M}$ of each dNTP, $0.4 \mu \mathrm{M}$ of each primer and 0.625 units of Taq DNA polymerase (Life Technologies). Samples were overlayed with mineral oil and subjected to 25 cycles of amplification in a DNA thermal cycler (Robocycler, Stratagene). The cycle was: denaturation, $94^{\circ} \mathrm{C}$ for $1 \mathrm{~min}$; annealing, $62-66^{\circ} \mathrm{C}$ depending on the primer pair, for $1 \mathrm{~min}$; extension, $72^{\circ} \mathrm{C}$ for $1 \mathrm{~min}$. The negative controls contained all reagents except template DNA. For visualisation of 
PCR products, 7- $\mu 1$ samples of the product were subjected to electrophoresis in agarose (Sigma Type II EEO) $1 \%$ gels, stained with ethidium bromide $0.5 \mu \mathrm{g} / \mathrm{ml}$ and viewed under UV illumination. Ampli- fication was also performed directly by suspending a single colony in $100 \mu \mathrm{l}$ of distilled water, vortex mixing and using $2.5 \mu \mathrm{l}$ of cell suspension in $25 \mu \mathrm{l}$ of reaction mix as above.

Table 1. Identification assays for CNS

\begin{tabular}{|c|c|c|c|c|c|}
\hline $\begin{array}{l}\text { Biotype (and } \\
\text { strain number) [5] }\end{array}$ & $\begin{array}{l}\text { Culture collection } \\
\text { designation }\end{array}$ & $\begin{array}{l}\text { ATB } \\
\text { identification }\end{array}$ & $\begin{array}{l}\text { Hind III/Eco RI } \\
16 \mathrm{~S} \text { ribotype }\end{array}$ & $\begin{array}{l}\text { Key } \\
\text { PCR }\end{array}$ & $\begin{array}{l}\text { New taxonomic } \\
\text { designation }\end{array}$ \\
\hline M3g $(601)$ & $\begin{array}{l}\text { NCTC } 11045 \\
\text { S. } \text { capitis }^{\mathrm{T}}\end{array}$ & S. capitis $99.9 \%$ & $\mathrm{H} 1$ & $S c p+$ & S. capitis \\
\hline SVIa(471) & $\ldots$ & S. capitis $81.2 \%$ & H1 & $S c p+$ & S. capitis \\
\hline $\operatorname{SVIb}(520)$ & & S. capitis $81.2 \%$ & $\mathrm{H} 1$ & Scp+ & S. capitis \\
\hline SIIa & $\begin{array}{l}\text { NCTC } 11047 \\
\text { S. epidermidis }{ }^{\mathrm{T}}\end{array}$ & S. epidermidis $97.9 \%$ & $\mathrm{H} 2$ & Sept & S. epidermidis \\
\hline SIIb & $\begin{array}{l}\text { NCTC } 9865 \\
\text { S. epidermidis }\end{array}$ & S. epidermidis $99.5 \%$ & $\mathrm{H} 2 \mathrm{a}$ & Sep+ & S. epidermidis \\
\hline $\operatorname{SIIc}(205)$ & $\begin{array}{l}\text { NCTC } 10519 \\
\text { S. epidermidis }\end{array}$ & S. epidermidis $97.4 \%$ & $\mathrm{H} 2 \mathrm{a}$ & Sep+ & $S$. epidermidis \\
\hline $\operatorname{SIIb}(176)$ & & Unidentified & $\mathrm{H} 2 \mathrm{~b}$ & Sep+ & S. epidermidis \\
\hline $\operatorname{SIVc}(598)$ & $\begin{array}{l}\text { NCTC } 11042 \\
\text { S. haemolyticus }\end{array}$ & S. haemolyticus $99.9 \%$ & $\mathrm{H} 3$ & Shl+ & S. haemolyticus \\
\hline SIVab & $\begin{array}{l}\text { NCTC } 4276 \\
\text { S. warneri }\end{array}$ & S. haemolyticus $99.8 \%$ & $\mathrm{H} 3 \mathrm{a}$ & Shl+ & S. haemolyticus \\
\hline SVIc(499) & $\ldots$ & S. haemolyticus $99.9 \%$ & $\mathrm{H} 3 \mathrm{a}$ & Shlt+ & S. haemolyticus \\
\hline M3e(462) & $\ldots$ & S. haemolyticus $99.9 \%$ & $\mathrm{H} 3 \mathrm{~b}$ & Shl+ & S. haemolyticus \\
\hline SVId(452) & $\ldots$ & S. haemolyticus $99.9 \%$ & $\mathrm{H} 4$ & Shl+ & S. haemolyticus \\
\hline $\operatorname{SVb}(255)$ & $\begin{array}{l}\text { NCTC } 11320 \\
\text { S. hominis }\end{array}$ & $\begin{array}{l}\text { Unidentified } \\
\text { S. hominis } 99.7 \%\end{array}$ & $\begin{array}{l}\mathrm{H} 4 \mathrm{a} \\
\mathrm{H} 5\end{array}$ & $\begin{array}{l}\text { Shlt } \\
\text { Shnt }\end{array}$ & $\begin{array}{l}\text { S. haemolyticus } \\
\text { S. hominis }\end{array}$ \\
\hline $\operatorname{SIVb}(217)$ & $\begin{array}{l}\text { NCTC } 7612 \\
\text { S. warneri }\end{array}$ & S. hominis $99.9 \%$ & H5 & Shnt & S. hominis \\
\hline SVab(570) & & S. hominis $99.7 \%$ & $\mathrm{H} 5$ & $\operatorname{Shn}+$ & S. hominis \\
\hline $\mathrm{M} 3 \mathrm{a}(214)$ & $\begin{array}{l}\text { NCTC } 7292 \\
\text { S. saprophyticus }{ }^{\mathrm{T}}\end{array}$ & S. saprophyticus $99.9 \%$ & H6 & Ssp+ & S. saprophyticus \\
\hline M3b & $\begin{array}{l}\text { NCTC } 7526 \\
\text { S. saprophyticus }\end{array}$ & Unidentified & H6а & Ssp+ & S. saprophyticus \\
\hline $\mathrm{M} 3 \mathrm{c}(216)$ & $\begin{array}{l}\text { NCTC } 7540 \\
\text { S. saprophyticus }\end{array}$ & S. hominis $95.4 \%$ & H6a & Ssp+ & S. saprophyticus \\
\hline \multirow[t]{3}{*}{$\operatorname{SVc}(213)$} & $\begin{array}{l}\text { NCTC } 10516 \\
\text { S. saprophyticus }\end{array}$ & S. saprophyticus $99.9 \%$ & H6a & Ssp+ & S. saprophyticus \\
\hline & $\begin{array}{l}\text { NCTC } 12218 \\
\text { S. schleiferi }\end{array}$ & S. schleiferi $99.8 \%$ & $\mathrm{H} 7$ & $S s c+$ & S. schleiferi \\
\hline & $\begin{array}{l}\text { NCTC } 12103 \\
\text { S. sciuri }\end{array}$ & S. sciuri $98.4 \%$ & E1 & Ssr+ & S. sciuri \\
\hline $\mathrm{M} 5 \mathrm{~b}(274)$ & $\ldots$ & S. sciuri $99.9 \%$ & Ela & $S s r+$ & S. sciuri \\
\hline SVId & $\begin{array}{l}\text { NCTC } 11044 \\
\text { S. } \text { warneri }^{\mathrm{T}}\end{array}$ & S. warneri $99.9 \%$ & H8 & Swn+ & S. warneri \\
\hline SIVaa(202) & $\begin{array}{l}\text { NCTC } 10518 \\
\text { S. warneri }\end{array}$ & S. warneri $91.9 \%$ & $\mathrm{H} 8$ & Swn+ & S. warneri \\
\hline $\operatorname{SVaa}(463)$ & $\ldots$ & S. warneri $91.9 \%$ & $\mathrm{H} 8$ & Swnt & S. warneri \\
\hline $\begin{array}{l}\operatorname{MXa}(473) \\
\operatorname{SIIIb}(200)\end{array}$ & $\begin{array}{l}\text { NCTC } 10530 \\
S . \text { chromogenes }^{\mathrm{T}}\end{array}$ & $\begin{array}{l}\text { S. cohnii } 99.8 \% \\
\text { S. chromogenes } 78.1 \%\end{array}$ & $\begin{array}{l}\text { E2a } \\
\text { E3 }\end{array}$ & $\begin{array}{l}- \\
-\end{array}$ & $\begin{array}{l}\text { S. cohnii } \\
\text { S. chromogenes }\end{array}$ \\
\hline SIIIa(301) & $\begin{array}{l}\ldots \\
\text { NCTC } 10350 \\
\text { S. hyicus }{ }^{\mathrm{T}}\end{array}$ & $\begin{array}{l}\text { S. chromogenes } 99.6 \% \\
\text { S. hyicus } 86.9 \%\end{array}$ & $\begin{array}{l}\text { E3a } \\
\text { E4 }\end{array}$ & $\begin{array}{l}- \\
-\end{array}$ & $\begin{array}{l}\text { S. chromogenes } \\
\text { S. hyicus }\end{array}$ \\
\hline $\mathrm{M} 6 \mathrm{a}(224)$ & $\begin{array}{l}\text { NCTC } 10517 \\
\text { S. xylosus }\end{array}$ & S. xylosus $99.9 \%$ & E5 & - & S. xylosus \\
\hline $\operatorname{SIa}(233)$ & $\begin{array}{l}\text { NCTC } 8532 \\
\text { S. aureus }\end{array}$ & S. aureus $99.9 \%$ & H9 & - & S. aureus \\
\hline $\operatorname{SIIIC}(602)$ & $\begin{array}{l}\text { NCTC } 11046 \\
\text { S. simulans }\end{array}$ & S. simulans $99.9 \%$ & $\mathrm{H} 10$ & - & S. simulans \\
\hline \multirow[t]{3}{*}{ SVe(204) } & $\begin{array}{l}\text { NCTC } 7990 \\
\text { S. lugdunensis }\end{array}$ & S. lugdunensis $99.8 \%$ & H11 & - & S. lugdunensis \\
\hline & $\begin{array}{l}\text { NCTC } 12195 \\
\text { S. gallinarum }\end{array}$ & S. gallinarum $99.9 \%$ & $\mathrm{H} 12$ & - & S. gallinarum \\
\hline & $\begin{array}{l}\text { NCTC } 12101 \\
\text { S. auricularis }\end{array}$ & S. auricularis $99.9 \%$ & $\mathrm{H} 13$ & - & S. auricularis \\
\hline $\operatorname{SIb}(426)$ & $\ldots$ & S. intermedius $99.8 \%$ & $\mathrm{H} 14$ & - & S. intermedius \\
\hline SVIe(484) & $\ldots$ & Unidentified & H15, E6 & - & Unidentified \\
\hline M5a(88) & $\ldots$ & Unidentified & H16, E7 & $(S s p+)$ & Unidentified \\
\hline
\end{tabular}




\section{Results}

\section{Biochemical test identification}

The results of the ATB 32 Staph gallery for each strain are shown in Table 1 . There were three cases where the ATB phenotype contradicted the attributed species name of the NCTC strain. ' $S$. warneri' NCTC 4276 was identified with $99.8 \%$ probability as $S$. haemolyticus, and ' $S$. warneri' NCTC 7612 was identified with $99.9 \%$ probability as $S$. hominis. In these first two cases the ATB phenotype was in agreement with genetic criteria (see below), illustrating the relative accuracy of the ATB gallery test format. In a third case, strain NCTC 7540 , deposited as $S$. saprophyticus, was identified with $95.4 \%$ probability by ATB as $S$. hominis while genetic criteria (see below) agreed with the species name given by NCTC.

In five cases ATB failed to assign a species name to a strain. These were strains 176 (Marples biotype SIIb), 255 (Marples biotype SVb), 484 (Marples biotype SVIe), 88 (Marples biotype M5a) and strain NCTC 7526 , deposited in the culture collection as $S$. saprophyticus.

\section{$16 S$ ribotyping}

All strains were analysed for polymorphism around the $r r n$ loci (16S ribotype). Candidate taxon-specific ribotypes were detected in genomic Southern blots. For 32 strains, such ribotypes were found in Hind III $(\mathrm{H})$ blots, and for 11 strains they were found in Eco RI (E) blots, (Fig. 1a and b). In both cases, 5-10 bands ranging in size from $0.5 \mathrm{~kb}$ to $15 \mathrm{~kb}$ were detected. There were 10 clusters of strains whose $16 \mathrm{~S}$ ribotypes (H1, H2, H3, H4, H5, H6, H8, E1, E2, E3) were identical or closely related (one-to-three band differences). The fact that these $16 \mathrm{~S}$ ribotypes were speciesspecific was supported by comparison with the data of De Buyser et al. [12] and was additionally confirmed by PCR data (see below). The NCTC type strains $S$. aureus $^{\mathrm{T}}$, S. simulans ${ }^{\mathrm{T}}$, S. lugdunensis ${ }^{\mathrm{T}}$, S. gallinarum $^{\mathrm{T}}$, S. auricularis $^{\mathrm{T}}, S$. hyicus ${ }^{\mathrm{T}}$ and $S$. schleiferi $^{\mathrm{T}}$, represented in this study by one reference strain each, all exhibited unique $16 \mathrm{~S}$ ribotypes. 16S ribotypes are summarised in Table 1.

In three of the five cases in which ATB tests failed to identify strains (see above), 16S ribotype helped assign them to a specific cluster. These were strain 176 , which was included in ribotype group $\mathrm{H} 2$; strain 255 , which was included in ribotype group $\mathrm{H} 3$, and strain NCTC 7526, which was included in ribotype group H6. The other two strains (484 and 88) showed uncommon Hind III and Eco RI ribotypes and could not be assigned to any specific group. In two of the reference strains, the $16 \mathrm{~S}$ ribotype did not concur with that of the species under whose name it had been deposited in the NCTC. These were: 'S. warneri' NCTC 4276 (which exhibited a 16S ribotype related to that of $S$. haemolyticus $^{\mathrm{T}}$ ), and 'S. warneri' NCTC 7612 (which exhibited a ribotype identical to that of S. hominis $\left.{ }^{\mathrm{T}}\right)$.

\section{Design features of species-specific PCRs}

The 16S rRNA gene sequences of eight Staphylococcus species were retrieved from the GenBank database. The species and corresponding GenBank accession numbers were: S. capitis (L37599); S. epidermidis (L37605); S. haemolyticus (L37600); S. hominis (L37601); S. saprophyticus (L37596); S. schleiferi (S83568); S. sciuri (S835569) and S. warneri (L37603). The sequences were aligned by the Clustal $\mathrm{V}$ computer program [23]. As shown in Fig. 2, three regions of the gene were identified which included bases differing between species. They comprised blocks of $c$. 30 bases each, located downstream of bases 182, 436 and 998 (Escherichia coli numbering scheme). Primer pairs for species-specific PCRs were selected from within these blocks and were designed to ensure maximum primer specificity. Where possible, this was achieved by locating the most species-specific base positions at the $3^{\prime}$ ends of the primers. Their position and the length of their amplification products are also shown in Fig. 2. The primers were given acronyms as follows: $S$. capitis, 'Scp'; S. epidermidis, 'Sep'; S. haemolyticus, 'Shl'; S. hominis, 'Shn'; S. saprophyticus, 'Ssp'; S. schleiferi, 'Ssc'; S. sciuri, 'Ssr' and S. warneri, 'Swn'.

\section{Validation of PCR identification tests}

The eight primer pairs shown in Fig. 2 were tested against all the strains under study, leading to the identification of eight species-clusters. The results of the newly designed PCR assays are shown in Table 1, where only positive reactions are indicated. The primer pair $S c p$ identified $S$. capitis $^{T}$ and two strains, both

Fig. 1. Species-specific 16S ribotypes of CNS. A: Genomic DNA digested with Hind III and probed with 1500-bp intragenic fragment of the $16 \mathrm{~S}$ rRNA gene of $S$. epidermidis ${ }^{\mathrm{T}}$. Lanes 1-3, S. epidermidis strains $11047^{\top}, 10519,9865$; 4-6, S. warneri strains $11044^{\mathrm{T}}, 10518,463,7-10, S$. saprophyticus strains $7292^{\mathrm{T}}, 10516,7526,7540$; 11, no sample; 12-14, S. hominis strains $11320^{\mathrm{T}}, 7612,570 ; 15-17, S$. haemolyticus subgroup 1 strains $11042^{\mathrm{T}}, 4276,499 ; 18-19, S$. haemolyticus subgroup 2 strains 459,$255 ; \mathbf{2 0 - 2 2}, S$. capitis strains $11045^{\mathrm{T}}, 520,471 ; \mathbf{2 3}$, unidentified strain 484 . B: Genomic DNA digested with Eco RI and probed as above. Track 1, unidentified strain $88 ; 2,3, S$. chromogenes strains

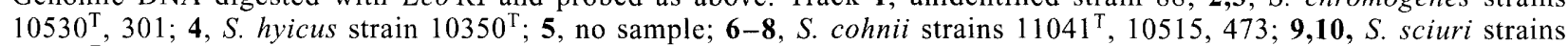
$12103^{\mathrm{T}}, 274$. 

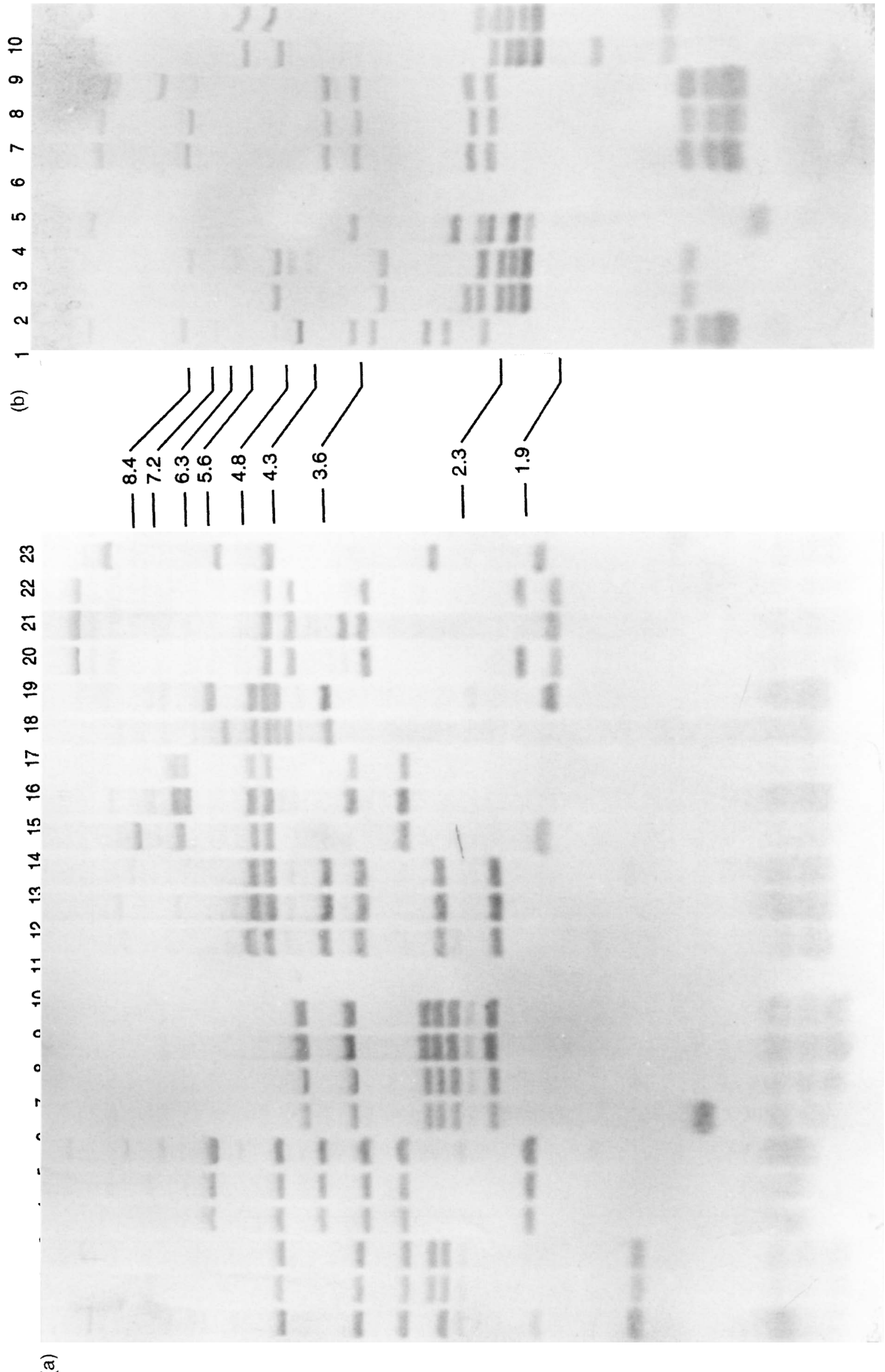


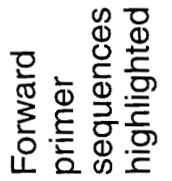
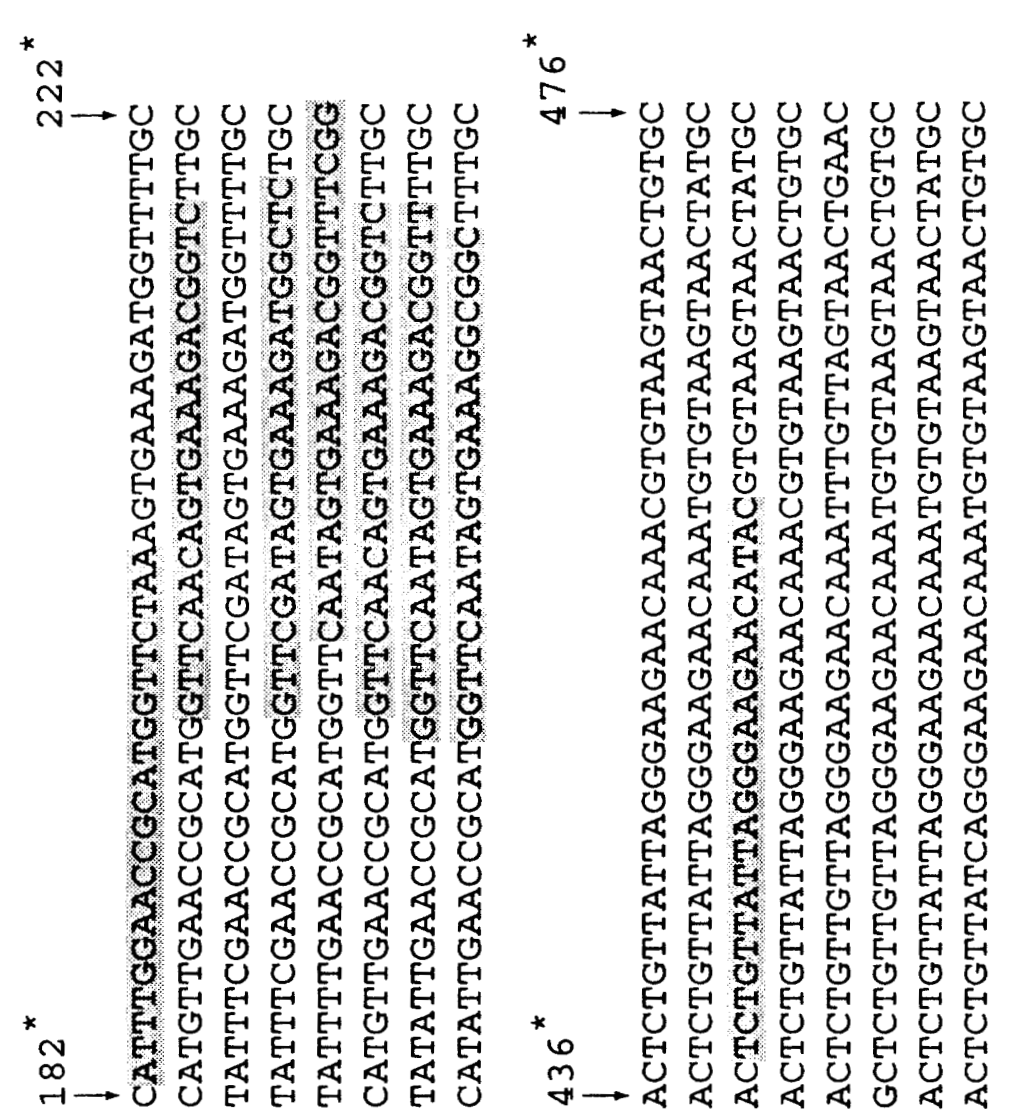

$*$
$\infty$
$n$
0
$n$

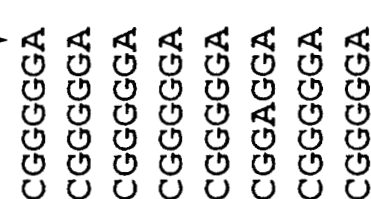

UU

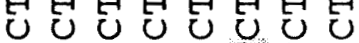

U $U$ O $\cup$ U E $U$

ช

GE EHE

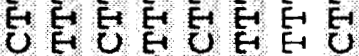

Uण 0 H

00090000

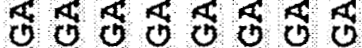

द स \& \&

पद द

000 ชै 00

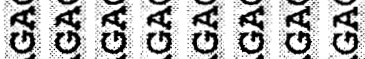

पद दूरद

तै

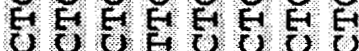

48478808

$\$ 8 \$ 40$ 웡

द्र

发芯通芯芯芯芯

$\rightarrow \in \in \in \in$

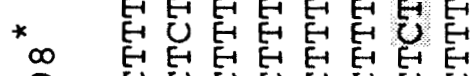

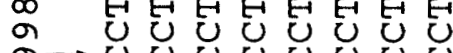

U U U

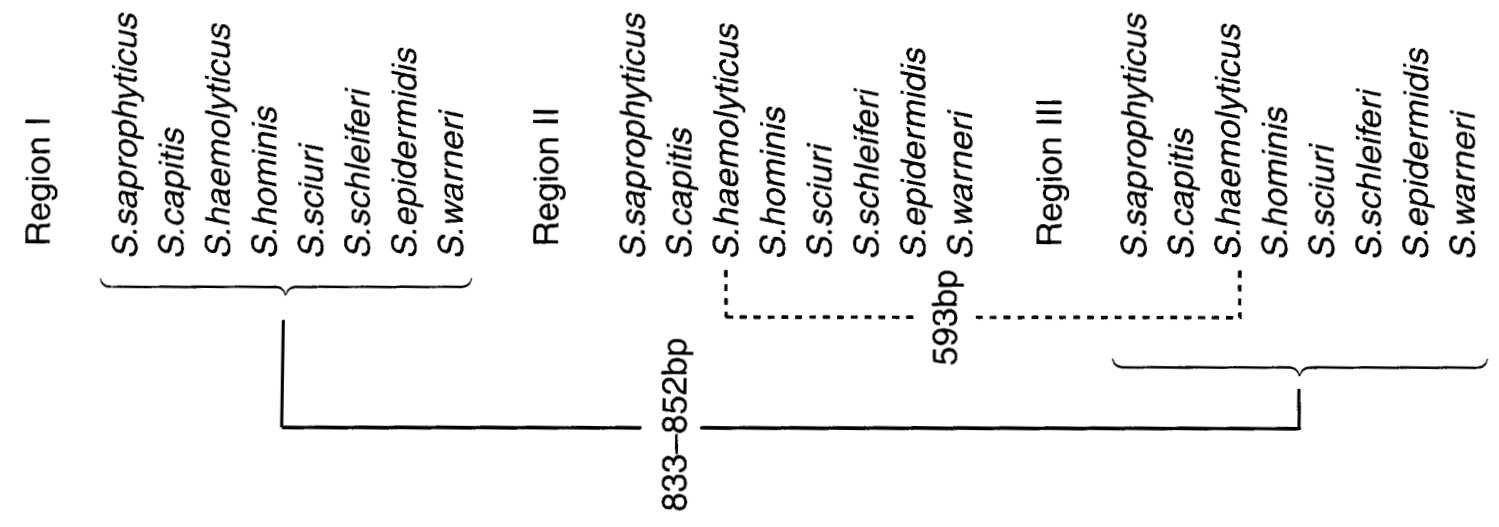

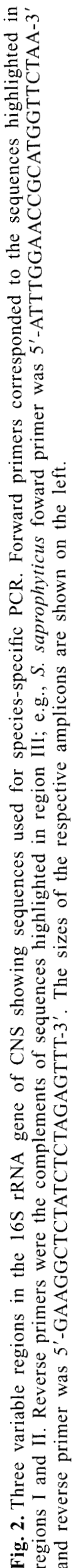


belonging to biotype SVI, both identified by ATB as $S$. capitis, and both with $16 \mathrm{~S}$ ribotypes identical to the type strain. The primer pair Sep identified the $S$. epidermidis type strain NCTC 11047 (biotype SIIa), strain NCTC 9865 (biotype SIIb) and strain NCTC 10519 (biotype SIIc). This was in agreement with the name under which these strains had been deposited in the culture collection, with ATB results, and with the fact that they shared closely related $16 \mathrm{~S}$ ribotypes. Sep primers also identified strain 176, belonging to Marples biotype SIIb, which exhibited a $16 \mathrm{~S}$ ribotype related to $S$. epidermidis ${ }^{\mathrm{T}}$, but was unidentifiable by ATB. The primer pair $S h l$ identified $S$. haemolyticus ${ }^{\mathrm{T}}$ and a cluster of strains whose identification was otherwise problematic. One of these was NCTC 4276, a strain belonging to biotype SIVab and deposited as ' $S$. warneri', but identified in this study by ATB as $S$. haemolyticus. Another was the previously unspeciated strain 255 , belonging to biotype $\mathrm{SVb}$, which was unidentifiable by ATB. Three other strains without previously assigned species names were also identified by primer pair $S h l$. They were strain 499 (biotype SIVc), strain 462 (biotype M3e) and strain 459 (biotype SVId). In all cases, PCR results concurred with ATB in identifying them as $S$. haemolyticus. Furthermore, identification of the above strains by primer pair Shl confirmed that there were two subgroups within that species with distinct ribotype clusters (based around $\mathrm{H} 3$ and $\mathrm{H} 4$ respectively), as has been observed previously [24]. Thus combining 16S ribotype with PCR identification gives a more complete picture of phylogenetic relationships than ribotype alone would have done.

The primer pair $S h n$ identified $S$. hominis ${ }^{\mathrm{T}}$, together with strain 570 (biotype SVab). Strain NCTC 7612 (biotype SIVb, deposited as ' $S$. warneri'), which was also identified by the $S h n$ primers, exhibited the same $16 \mathrm{~S}$ ribotype and ATB phenotype as $S$. hominis ${ }^{\mathrm{T}}$. Primer pair $S s p$ identified $S$. saprophyticus ${ }^{T}$ and three other NCTC strains. These were NCTC 7526 (biotype M3b), NCTC 7540 (biotype M3c) and NCTC 10516 (biotype SVc), all of which were deposited as $S$. saprophyticus in the culture collection, and shared the same $16 \mathrm{~S}$ ribotype as the species type strain. Of these three strains, however, only strain NCTC 10516 was identified as $S$ saprophyticus by ATB. The primer pair $S s c$ identified $S$. schleiferi $^{\mathrm{T}}$. The primer pair $S s r$ identified $S$. sciuri ${ }^{\mathrm{T}}$ and a strain belonging to biotype M5b, which shared its ATB phenotype and 16S ribotype. The primer pair $S w n$ identified $S$. warneri ${ }^{\mathrm{T}}$ and placed two other strains in that species. They were NCTC 10518 (belonging to biotype SIVaa) and strain 463 (biotype SVaa). These three strains shared the same ATB phenotype and the same $16 \mathrm{~S}$ ribotype, which we therefore consider characteristic of $S$. warneri. Although the primer pair Sep also detected $S$. capitis $^{\mathrm{T}}$, the latter species was easily differentiated by parallel assays with the primer pair $S c p$, which identified only $S$. capitis and exhibited no cross- reaction with any $S$. epidermidis strain. By comparison, in a previous report [17], PCR was unable to distinguish between $S$. epidermidis and $S$. capitis.

In one case, PCR and ATB identification were discordant. Strain NCTC 7540, deposited in the Culture Collection as $S$. saprophyticus, reacted with primer pair $S s p$ but was identified by ATB as ' $S$. hominis'. Its $16 \mathrm{~S}$ ribotype was related to that of $S$. saprophyticus ${ }^{\mathrm{T}}$, in agreement with the PCR result. Strain 88, belonging to biotype M5a, and whose identity could not be fully confirmed, was identified by $S s p$, but it had a ribotype unique in the study (Fig. 1b) and was unidentifiable by ATB.

PCR assays made directly from cells gave results which were as accurate and reproducible as those obtained from purified DNA, thus reducing the time required for identification to $<3 \mathrm{~h}$.

\section{Discussion}

Among the CNS, the most frequently isolated species in the clinical laboratory are $S$. epidermidis and $S$. saprophyticus. S. epidermidis has been reported to cause $>80 \%$ of the CNS bacteraemias that follow implant surgery, due perhaps to its presence in large numbers on human skin [25]. S. saprophyticus is an important causative agent of urinary tract infections in young women [26]. Hence, identification of CNS by phenotypic methods aims principally at distinguishing clearly between $S$. epidermidis and $S$. saprophyticus. However, phosphatase-negative variants of $S$. epidermidis can often be misidentified as $S$. hominis [1,17]. Moreover, in the present study, the ATB test gallery failed to identify two of four $S$. saprophyticus strains. The $S$. haemolyticus/S. hominis/S. warneri group similarly represents a problem for phenotypic identification schemes, because of weak or variable biochemical test results [27]. For instance, in the Baird-Parker scheme the biotypes were defined primarily by acidification of lactose or mannitol, while Kloos and Schleifer [3] differentiated S. hominis from S. warneri on the basis of a lactose positive or negative reaction, respectively. The results of the present study suggest that these phenotypic characters are only valid at a subspecific level. The fact that rarer species might appear in clinical samples further emphasises the need for their accurate identification [28].

The present study demonstrated PCR identification of CNS species, chosen in the first instance on the basis of their prevalence and difficulty of identification in the reference laboratory. Twenty-six of the 41 strains under investigation were identified by PCR as belonging to one of the eight species for which specific primer pairs had been designed. Among them, 10 reference strains belonging to Marples biotypes were speciated for the first time, the identity of 14 
NCTC reference strains was confirmed, and two NCTC reference strains were reassigned to different species. For 22 of these 26 strains there was complete agreement between identification by $\mathrm{PCR}, 16 \mathrm{~S}$ ribotype and ATB, supporting the validity of these PCRs as a rapid and accurate means to speciate CNS. In the other four cases there was concordance between PCR and $16 \mathrm{~S}$ ribotype identification. None of the $10 \mathrm{NCTC}$ strains known to belong to species for which primers had not been designed was misidentified by PCR, confirming the specificity of the eight primer pairs described. Two biotype reference strains gave conflicting results, ambiguous by all criteria, and are being studied further.

It is noteworthy that two NCTC strains were reassigned to different $\mathrm{CNS}$ species. In general, culture collections do not yet have molecular genetic means to verify the identity of strains lodged by depositors. Therefore, they may perpetuate errors in bacterial identification, an anomaly which could be corrected by the introduction of species-specific PCRs for genetic quality control.

We suggest that PCR offers an excellent method of molecular identification for CNS, to be used alone or in combination with phenotypic identification. We anticipate that the two systems would continue to be used together, as unusual biotypes may also provide typing information of epidemiological importance. Definitive PCR identification as described in this report can be made directly from colonies within $3 \mathrm{~h}$, considerable less than the time required for ribotyping (4-5 days). Thus, a high throughput of isolates can be identified. The application of the method to the detection of CNS directly from clinical samples should also prove useful in the hospital laboratory, where speed may be critical.

The rapidity and accuracy of the PCR assays described herein make them a useful tool for screening new taxa, and for ecological studies of CNS. PCR identification could help clarify the incidence and clinical significance of the rarer CNS species, which is probably underestimated by current phenotypic identification methods. In a two-step approach to identification, the Sep primers could be applied alone in the first instance, in parallel with ATB phenotypic gallery tests. This will identify $S$. epidermidis, to which the majority of CNS clinical isolates belong. Then, for example, Sep-positive strains showing unusual biochemical features (such as acidification of mannitol) could be tested against the $S c p$ primers. In such a way, the other primer sets may be applied selectively, to confirm or to resolve ATB identification data if one of the rarer species is implicated.

S. G. was the recipient of a fellowship from the University of Catania, Italy. We thank Dr P. P. Mortimer for critically reading the manuscript.

\section{References}

1. Kloos WE, Bannerman TL. Update on clinical significance of coagulase-negative staphylococci. Clin Microbiol Rev 1994; 7 : $117-140$.

2. Baird-Parker AC. A classification of Micrococci and Staphylococci based on physiological and biochemical tests. $J$ Gen Microbiol 1963; 30: 409-427.

3. Kloos WE, Schleifer KH. Simplified scheme for routine identification of human Staphylococcus species. $J$ Clin Microbiol 1975; 1: 82-88.

4. Marples RR. Taxonomic studies of Staphylococci and Micrococci. Zentralble Bakteriol Suppl 1981; 10: 9-13.

5. Marples RR, Richardson JF. Evaluation of a micromethod gallery (API Staph) for the identification of staphylococci and micrococci. J Clin Pathol 1982; 35: 650-656.

6. Freney J, Brun Y, Bes M et al. Staphylococcus lugdunensis sp nov. and Staphylococcus schleiferi sp. nov., two species from human clinical specimens. Int J Syst Bacteriol 1988; 38: 168 172.

7. Zimmerman RJ, Kloos WE. Comparative zone electrophoresis of esterases of Staphylococcus species isolated from mammalian skin. Can J Microbiol 1976; 22: 771-779.

8. Clink J, Pennington TH. Staphylococcal whole-cell polypeptide analysis: evaluation as a taxonomic and typing tool. $J$ Med Microbiol 1987; 23: $41-44$

9. Kotilainen P, Huovinen P, Eerola E. Application of gas-liquid chromatographic analysis of cellular fatty acids for species identification and typing of coagulase-negative Staphylococci. $J$ Clin Microbiol 1991; 29: 315-322.

10. Schleifer KH, Kroppenstedt RM. Chemical and molecular classifcation of staphylococci. J Appl Bacteriol Symp Suppl 1990; 19: 9S-24S.

11. Grimont F, Grimont PAD. Ribosomal ribonucleic acid gene restriction patterns as potential taxonomic tools. Ann Inst Pasteur Microbiol 1986; 137B: 165-175.

12. De Buyser M-L, Morvan A, Aubert S, Dilasser F, El Solh N. Evaluation of a ribosomal RNA gene probe for the identification of species and subspecies within the genus Staphylococcus. J Gen Microbiol 1992; 138: 889-899.

13. Thomson-Carter FM, Carter PE, Pennington TH. Differentiation of staphylococcal species and strains by ribosomal RNA gene restriction patterns. J Gen Microbiol 1989; 135: 20932097.

14. Bialkowska-Hobrzanska H, Harry V, Jaskot D, Hammemberg O. Typing of coagulase-negative staphylococci by Southern hybridization of chromosomal DNA fingerprints using a ribosomal RNA probe. Eur $J$ Clin Microbiol Infect Dis 1990; 9: $588-594$.

15. Wada A, Ohta H, Kulthanan K, Hiramatsu K. Molecular cloning and mapping of $16 \mathrm{~S}-23 \mathrm{~S}$ rRNA gene complexes of Staphylococcus aureus. J Bacteriol 1993; 175: 7483-7487.

16. Zakrzewska-Czerwiska J, Gaszewska-Mastalarz A, Pulverer G, Mordarski M. Identification of Staphylococcus epidermidis using a $16 \mathrm{~S}$ rRNA-directed oligonucleotide probe. FEMS Microbiol Lett 1992; 100: 51-58.

17. Hedin G. Comparison of genotypic and phenotypic methods for species identification of coagulase-negative staphylococcal isolates from blood cultures. APMIS 1994; 102: 855-864.

18. Brun $\mathrm{Y}$, Bes M, Boeufgras JM et al. International collaborative evaluation of the ATB 32 Staph gallery for identification of the Staphylococcus species. Int J Med Microbiol 1990; 273: 319-326.

19. Wilson K. Preparation of genomic DNA from bacteria. In: Current protocols in molecular biology. New York, John Wiley and Sons Inc., 1987: unit 2.4.1.

20. Baquar N, Burnens A, Stanley J. Comparative evaluation of molecular typing of strains from a national epidemic due to Salmonella brandenburg by rRNA gene and IS200 probes and Pulsed-Field Gel Electrophoresis. J Clin Microbiol 1994; 32 1876-1880

21. Sambrook J, Fritsch EF, Maniatis T. Molecular cloning, A laboratory manual. 2nd edn. Cold Spring Harbor, NY, Cold Spring Harbor Laboratory. 1989

22. Lucas K, Busch M, Mossinger S, Thompson JA. An improved microcomputer programme for finding gene- or family-specific oligonucleotides suitable as primers for polymerase chain reactions or as probes. Comput Appl Biosci 1991; 7: 525-529.

23. Higgins DG, Sharp PM. Fast and sensitive multiple sequence 
alignments on a microcomputer. Comput Appl Biosci 1989; 5: $151-153$

24. Cookson BD, Stapleton P, Ludlam H. Ribotyping of coagulasenegative staphylococci. J Med Microbiol 1992; 36: $414-419$.

25. Schumacher-Perdreau F. Clinical significance and laboratory diagnosis of coagulase-negative Staphylococci. Clin Microbiol Newslett 1991; 13: 13.

26. Marrie TJ, Kwan C, Noble A, West A, Duffield L. Staphylococcus saprophyticus as a cause of urinary tract infections. $J$ Clin Micrbiol 1982; 16:427-431.

27. Fleurette J, Brun Y, Coulet M, Forey F. Infections caused by coagulase-negative staphylococci other than $S$. epidermidis and S. saprophyticus. Zentralbl Bakteriol Suppl 1987; 16: $195-208$.

28. Kleeman KT, Bannerman TL, Kloos WE. Species distribution of coagulase-negative staphylococcal isolates at a community hospital and implications for selection of staphylococcal identification procedures. J Clin Microbiol 1993; 31: 13181321 . 